\title{
Caudal epidural steroid injection ultrasound-guided versus fluoroscopy- guided in treatment of refractory lumbar disc prolapse with radiculopathy
}

\author{
Mohamed Ahmed Elashmawy ${ }^{1}$, Reham M. Shaat ${ }^{1 *}$, A. M. Abdelkhalek² and Ebrahim El Boghdady ${ }^{1}$
}

\begin{abstract}
Background: Lumbar disc prolapse is a localized herniation of disc beyond intervertebral disc space and is the most common cause of sciatica; the aim of this study is to investigate the efficacy of ultrasound (US)-guided caudal epidural steroid injection (CESI) compared with fluoroscopy (FL)-guided CESI in treatment of patients with refractory lumbar disc prolapse (LDP) with radiculopathy.

Results: At the beginning of the study, there was no significant difference between both groups in all parameters.

(a) Group 1 had significantly improved the straight leg raising and modified Schober tests, VAS, and ODI at 1month and 3-month post-injection evaluation in comparison to baseline recordings ( $p<0.001$ ); (b) Group 2 had significantly improved the straight leg raising and modified Schober tests, VAS, and ODI at 1-month and 3-month post-injection evaluation in comparison to baseline recordings ( $p<0.001)$; and (c) US-guided CESI was not statistically different from the FL-guided CESI in the improvement of the straight leg raising $(p=0.87,0.82)$ and modified Schober tests $(p=0.87,0.82)$ as well as VAS $(p=0.40,0.43)$ and ODI $(p=0.7,0.2)$ at 1 -month and 3month post-injection evaluation. In a multivariate analysis using $\mathrm{Cl}=95 \%$, the significant predictors for a successful outcome were duration $<6$ months $(p=0.03, \mathrm{OR}=2.25)$, target level not L2-3/L3-4 $(p<0.001, \mathrm{OR}=4.13)$, and LDP other than foraminal type $(p=0.002, \mathrm{OR}=3.78)$. However, age $<40$ years was found to be non-significant in predicting a successful outcome $(p=0.38, \mathrm{OR}=0.98)$.
\end{abstract}

Conclusion: US is excellent in guiding CESI with similar treatment outcomes as compared with FL-guided CESI.

Trial registration: ClinicalTrials.gov Identifier: NCT03933150.

Keywords: Caudal epidural injection, Ultrasound, Fluoroscopy, Corticosteroids

\section{Background}

A lumbar disc prolapse (LDP) is the most frequently recognized reason for radicular pain. It is strongly related to low back pain (LBP) and sciatica in humans, which is a widespread and incapacitating musculoskeletal disorder with considerable social and economic importance

\footnotetext{
* Correspondence: rehamshaat@mans.edu.eg; reham1975@yahoo.com; rehamshaat@gmail.com

${ }^{1}$ Faculty of Medicine, Department of Rheumatology and Rehabilitation, Mansoura University, Mansoura, Egypt

Full list of author information is available at the end of the article
}

[1]. Different conservative, nonsurgical varieties for treating LDP or radicular pain exist, including medications, physical therapy, manipulation and alternative therapy [2]. If conservative treatment fails, then surgery (the most invasive treatment modality) is commonly carried out for chronic persistent pain of disc herniation with or without radiculopathy, axial or discogenic pain, spinal canal stenosis, and degenerative spondylolisthesis [3]. Unfortunately, surgery is associated with a failure rate of $25 \%$ in well-reviewed patients. Due to comorbid factors, no longer everyone who is symptomatic is a 
candidate for surgery; some disc protrusions and small disc herniation are not amenable to surgical interventions [4]. Epidural steroid injection (ESI) is highlighted amongst the most widely recognized nonsurgical treatments for LDP [5]. Epidural steroid injection is administered by the way of having access to the lumbar epidural space through several routes including interlaminar, caudal, and transforaminal [6]. Caudal epidural steroid injection (CESI) is regarded as the most secure and least demanding with minimal risk of coincidental dural puncture, and favorable modality in post-surgery syndrome, despite the fact that requiring generally high volumes of injectate [7]. Successful caudal CESI depends on the precise placement of a needle through the sacral hiatus (SH) into the epidural space. Presumably, blind CESI without guidance is associated with wrong placement of a needle at a frequency of 25 to $38 \%$ of cases even by experienced physicians [8]. Studies on fluoroscopy (FL)-guided injections recommended that caudal epidural injection (CEI) should proceed underneath FL guidance with contrast media. However, the application of FL requires careful consideration because of the likelihood of ionizing radiation exposure [9]. Ultrasound (US) was found very excellent in localizing the $\mathrm{SH}$ and guiding needle directly into the caudal epidural space [10]. A lot of studies described using FL after contrast injection to confirm the position of a caudal needle placed under US guidance and reported a $100 \%$ success rate [11]. The aim of this work is to investigate the efficacy of USguided CESI compared with FL-guided CESI in the treatment of patients with refractory LDP with radiculopathy.

\section{Methods}

This study included 228 patients suffering from LDP with radiculopathy, recruited from the outpatient clinic of the Rheumatology and Rehabilitation Department at University Hospital; they were assessed for eligibility to participate in this study.

Those who met the inclusion criteria were selected. Conversely, those who did not meet inclusion criteria or met the exclusion criteria were excluded. Accordingly, 136 patients who met the inclusion criteria were divided into two groups:

- Group 1: Included 68 patients allocated for USguided CESI, 3 patients went to spinal surgery, did not receive an intervention, 6 patients lost during follow-up, and finally data was analyzed for 59 patients.

- Group 2: Included 68 patients allocated FL-guided CESI, 2 patients went to spinal surgery, did not receive an intervention, 4 patients lost during followup, and finally data was analyzed for 62 patients.

\section{Inclusion criteria}

Patients with LDP with unilateral radiculopathy diagnosed by routine clinical examination and MRI, in whom conservative treatment (medical treatment and physiotherapy) failed for more than 6 weeks and refuse surgery or were unfit for surgery, are included.

\section{Exclusion criteria}

Vertebral fractures, direct trauma, spinal inflammatory disease, spinal infection, bleeding tendency, LBP with tumors, bilateral radiculopathy, cauda equina syndrome, spinal canal stenosis, post-laminectomy surgery, diabetic, and hypertensive patients are excluded.

\section{Data collection}

Baseline clinical data collected by interviewing the participants included demographic characteristics, disease duration, and history of associated medical conditions such as diabetes mellitus, hypertension, spinal trauma (direct or indirect, previous spinal operation), and history of other illnesses such as cancer, abdominal, or pelvic diseases.

\section{Clinical examination}

All patients were subjected to general systemic examination, the local musculoskeletal examination of all the joints with stress on lumbar spine examination, special tests as straight leg raising test, modified Schober test, and neurological examination to lower extremity to reveal the occurrence of the lumbar radiculopathy.

\section{Laboratory assessment}

Blood samples were taken and analyzed for measuring complete blood count, erythrocyte sedimentation rate, random blood glucose, and C-reactive protein.

\section{Imaging}

MRI is the imaging modality of choice, as it has the advantage of not using ionizing radiation and has good visualizing capacities especially of the soft tissue [12].

\section{Study design}

The study is a randomized controlled clinical trial.

\section{Type of randomization}

After baseline evaluation, the eligible patients $(n=136)$ were randomly allocated into treatment groups by means of block randomization (size of block $=4$, with last block size $=2$ ). The patients in each block were randomized by the use of a sealed envelope. Patients and doctors assessing outcomes were blind to the method of injection. After the inclusion of a patient, a physiatrist drew an envelope and opened it (Fig. 1). 


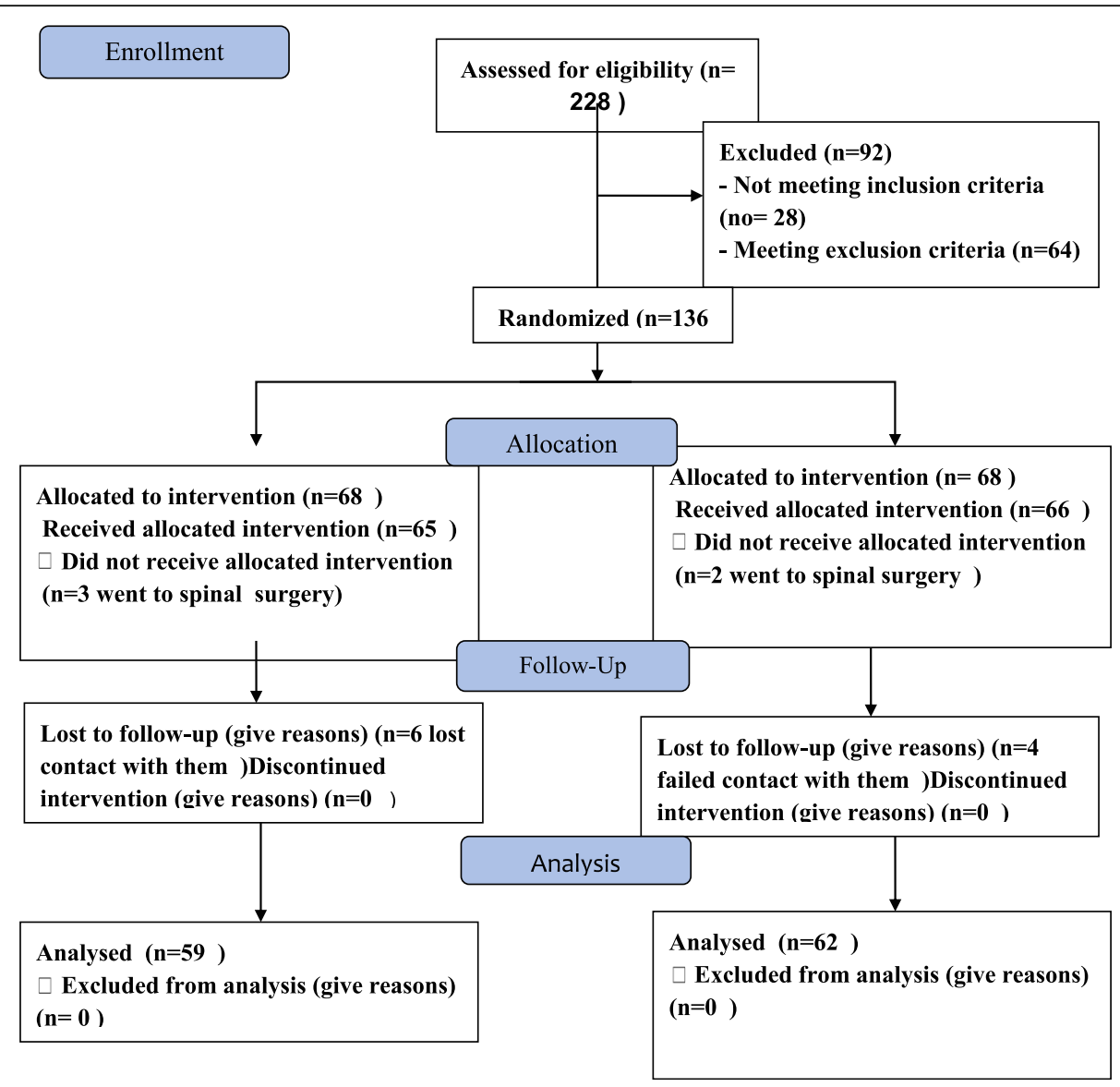

Fig. 1 Subjects flow diagram

\section{Sample size}

This is a controlled randomized clinical trial that proposes to assess the effectiveness of ultrasound-guided vs. fluoroscopy-guided caudal epidural steroid injection for the treatment of unilateral lower lumbar radicular pain. A previous study showed that a difference in the Oswestry Disability Index of 2.42 between the two procedures was clinically significant with a standard deviation of 4.74. To calculate the sample size with the level of significance $=5 \%$, power $=80 \%$, and type of test = two-sided, the following formula is used:

$$
n=\left[2 \mathrm{SD}^{2}\left(\mathrm{Z}_{\alpha / 2}+\mathrm{Z}_{\beta}\right)^{2}\right] / \mathrm{d}^{2}
$$

where $n=$ sample size required in each group, $Z_{\alpha / 2}=$ 1.96 at type 1 error of $5 \%$

$Z_{\beta}=0.842$ at $80 \%$ power, and $d=$ effect size, the difference between mean values. Based on the above formula, the sample size required per group is 60.2. Hence, the total sample size required is 120 .

Therefore, a sample size of 120 patients, 60 in each arm, is sufficient to detect a clinically important difference between ultrasound-guided vs. fluoroscopyguided caudal epidural steroid injection for the treatment of unilateral lower lumbar radicular pain using a two-tailed $t$ test of the difference between means with $80 \%$ power and a $5 \%$ level of significance.

All the eligible patients were treated with either USguided or FL-guided CESI and were administered a mixture of $20 \mathrm{cc}(0.5 \%$ lidocaine $18.0 \mathrm{ml}$ and $2 \mathrm{ml}$ of triamcinolone acetonide $40 \mathrm{mg} / 1 \mathrm{ml}$ ) [13].

\section{Intervention}

Ultrasound-guided CESI (Group 1) All the injection procedures were performed as an outpatient clinic setting. We used Acuson P300 (Siemens, Italy) with a linear transducer at 6 to $12 \mathrm{MHz}$ as the US instrument, and another curved transducer at $2-5 \mathrm{MHz}$ was available for obese patients.

First, the US probe was placed transversely at the midline to obtain the $\mathrm{SH}$ transverse image with the patient in the prone position (Supplementary Fig. 1).

Two sacral cornua appeared as hyper-echogenic structures with an inverted $\mathrm{U}$ shape, and then, $\mathrm{SH}$ was 
identified easily. At this level, the ultrasound transducer was rotated $90^{\circ}$ to obtain the longitudinal view of $\mathrm{SH}$.

Before CESI, the blood vessels were identified by power Doppler imaging. With the help of an assistant, an interventionalist, wearing sterile gloves, set up the equipment needed for the injection on a table covered with a sterile drape. The sacrococcygeal area was prepared using an iodine-based povidone solution and an alcohol solution.

A spinal needle (BD Spinal Needle Quinke Type Point, Becton Dickinson S A, Madrid, Spain) of 22-gauge and 3.5 -inch was used. Under longitudinal view, the block needle was inserted using the "in-plane" technique. The block needle was visualized in real-time, piercing the SCL until "pop" or "give" feeling of SCL penetration, entering the $\mathrm{SH}$, but could not be visualized beyond the apex of SH (Supplementary Fig. 2). Therefore, the advancement of needle tip beyond the apex of $\mathrm{SH}$ was limited to $5 \mathrm{~mm}$ to avoid the dural puncture because the distance between the apex of $\mathrm{SH}$ and dural sac termination can be as short as less than $6 \mathrm{~mm}$ [14].

After introducing the needle under longitudinal view, the US transducer position could be changed by placing it transversely across the $\mathrm{SH}$ and obtaining the image of the two sacral cornua with the needle out of plane. While we injected the material, the injectate will appear to the right, to the left, or to the center, and then, we modify the position of the needle to the affected side (Supplementary Fig. 3).

First, we checked the absence of the blood in the syringe before furthering the needle advancement and then performed an aspiration test to check for the presence of the blood and cerebrospinal fluid. If either method identified the blood, the needle was repositioned. If this technique identified CSF, the procedure was aborted and repeated after 2 weeks. After confirming the absence, first 1 to $2 \mathrm{~mL}$ of $1 \%$ lidocaine test dose was injected. The flow was observed using the color Doppler mode of US. We defined a positive spectrum as being observed the unidirectional flow of the solution with 1 dominant color through the epidural space beneath the SCL, without other directional flow of multiple colors. If other directional flow was detected, we reset the needle under US guidance and confirmed the needle position.

The following steps were initiated after monitoring of the onset of clinical manifestations such metallic taste, dizziness, tachycardia, lower extremity paresthesia, auditory changes, slurred speech, and motor ataxia for 1 to $2 \mathrm{~min}$. Then, we injected the treatment drug $(0.5 \%$ lidocaine $18.0 \mathrm{~mL} \& 2 \mathrm{ml}$ of triamcinolone acetonide $40 \mathrm{mg}$ / $1 \mathrm{ml}$ ) in the absence of such abnormal findings.

Fluoroscopy-guided CESI (Group 2) All the injection procedures were performed in a specialized room with a
FL device in the radiology department. We used a FL device GS 1004 with ALLURA XPER FD 20 system (Philips, Holland) with X-ray tube housing assembly, X-ray tube, beam-limiting device, and image receptor.

The patients were asked to lie on the FL table in a prone position. A pillow was placed under the hips to tilt the pelvis and bring the $\mathrm{SH}$ into greater prominence. Consequently, in the lateral view of $\mathrm{FL}$, the $\mathrm{SH}$ was normally visualized as a translucent opening toward the base of the sacral canal (SC). Recognition of the coccyx immediately caudal also assisted with localization of the SH.

The sacrococcygeal area was prepared using an iodinebased povidone solution and an alcohol solution. The interventionist then localized the coccyx tip through palpation with a sterilized middle finger. Likewise, palpation of the coccyx and the sacral cornua by the clinician to help distinguish the insertion point of a needle.

A spinal needle (BD Spinal Needle Quinke Type Point, Becton Dickinson S A, Madrid, Spain) of 22-gauge and 3.5-inch was used.

The block needle trajectory was visualized and navigated accordingly into the SC. The needle should not be progressed beyond the foramen of S3 to avoid harming the sacral nerve roots and to limit the risk of subarachnoid or subdural placement.

We checked the absence of blood in the syringe before the needle advancement. The inhalation test was performed to check CSF leakage. We injected 1 $\mathrm{mL}$ of contrast media (Omnipaque300; GE Healthcare, Carrigtohill, Co., Cork, Ireland) before drug injection. By injecting contrast medium under FL, the placement of the needle tip within the sacral epidural space was verified, and placement either intravascular or intrathecal could be ruled out (Supplementary Fig. 4).

First, we injected 1 to $2 \mathrm{~mL}$ of $1 \%$ lidocaine as a test dose and monitored for any clinical symptoms such as metallic taste, dizziness, tachycardia, lower extremity paresthesia, auditory changes, slurred speech, and motor ataxia for 1 to $2 \mathrm{~min}$. We injected $20 \mathrm{cc}$ of the treatment drug $(0.5 \%$ lidocaine $18.0 \mathrm{~mL} \& 2 \mathrm{ml}$ of triamcinolone acetonide $40 \mathrm{mg} / 1 \mathrm{ml}$ ) in the absence of such abnormal findings.

Post injection care for both groups:

Rest for 1 day.

The patient immediately returns to work 2 days after injection.

$\bigcirc$ Pain medication in the form of paracetamol only was allowed for the next 3 months if needed. The patients were instructed to stop analgesics $48 \mathrm{~h}$ before the visit to allow proper symptom assessment.

$\bigcirc$ Physical therapy or exercise was not allowed. 


\section{Outcome measures Pain visual analog scale}

The VAS-pain score is composed of a continuous horizontal line. This line is $100 \mathrm{~mm}$ in length. To measure the intensity of pain, the score is anchored by ( 0 score $=$ no pain $)$ at one end and $(100$ score $=$ worst imaginable pain) at the other end. The patient places a mark in the VAS line at the point which represents the intensity of his pain [15].

\section{Straight leg raising}

The patient lies on a table in a supine position. With the one handset over the knee of the leg being examined, the examiner applies enough firm pressure to keep the knee in full extension. With the alternate hand cupped under the heel, the examiner raises the straight limb gradually. Sciatic nerve compression is indicated if the pain is agonized or worsened on raising the leg to a level more than $25^{\circ}$ but lower than $75^{\circ}$ [16].

Modified Schober test

While the patient is standing erect, add marks at $5 \mathrm{~cm}$ below and $10 \mathrm{~cm}$ above the lumbosacral junction (dimples of venus), and the distance between the two marks is measured. Then, the measurement is repeated with the patient in full forward flexion. In general, the measure should increase by at least $5 \mathrm{~cm}$ to $21 \mathrm{~cm}$. An increase of less than $5 \mathrm{~cm}$ advocates decreased lumbar spinal mobility [17].

\section{Secondary outcome measures Oswestry Disability} Index [18]

It is a self-administered questionnaire compromised of 10 sections; each section is scored on a $0-5$ scale, 5 representing the greatest disability. It is composed of 10 short-term sectors. The index is calculated by dividing the summed score by the total possible score, after that it is multiplied by 100 and expressed as a percentage. Thus, for the not answered questions, the denominator is reduced by 5 for each.

The investigators who assessed the baseline data and outcome measures were blind to treatment procedures, and one investigator was responsible for intervention in the 2 groups.

Statistical analysis The collected data were computerized and statistically analyzed using the SPSS program (Statistical Package for Social Science) version 18.0.

Qualitative data were represented as frequencies and relative percentages.

$>$ Chi-squared test: it was used to calculate difference between qualitative variables in different groups. $>$ Quantitative data: it was expressed as mean \pm SD (standard deviation).
$>$ Independent $T$ test: it was used to calculate the difference between quantitative variables in 2 groups in normally distributed data.

$>$ Paired sample $T$ test was used to calculate the difference between quantitative variables in the same group at different times.

$>$ Mann-Whitney test: it was used to calculate differences between qualitative variables in 2 groups in not normally distributed data.

$>$ Paired sample Wilcoxon test: it was used to calculate difference between quantitative variables in the same group at different times in not normally distributed data.

$>$ McNemar test: it was used to find the relation between qualitative variables in the same group preand post-treatment.

The significance level for all abovementioned statistical tests done and the threshold of significance is fixed at $5 \%$ level ( $p$ value): " $p$ value of $>0.05$ indicates nonsignificant results, " $p$ value of $<0.05$ indicates significant results, and " $p$ value of $<0.01$ indicates a highly significant result.

\section{Results}

At entry of the study, this current RCT included 136 patients with lumbar disc prolapse who were randomized into two treatment groups, 68 patients in each group. From these patients, 59 patients in ultrasound-guided Group 1 and 62 patients in fluoroscopy-guided Group 2 completed the 3-month follow-up period, and hence, only the data of those patients were included in the statistical analyses.

As shown in Table 1, there were no statistical significant differences between two studied groups regarding age, BMI, or sex distribution.

Table 2 showed that there were no statistical significant differences between two studied groups regarding duration, target level, or type of lumbar disc, but there was statistical significant increase in time of procedure among Group 2.

As shown in Table 3, there was no statistical significant difference between two studied groups regarding VAS before and after injection. However, there was a statistical significant decrease in VAS in each group after 1 and 3 months of injection versus initial assessment. No statistical significance difference was found between VAS values at 1 month and 3 months value in both groups.

As shown in Table 4, there was no statistical significant difference between two studied groups regarding Modified Schober Test before or after injection. However, there was statistical significant increase regarding Modified Schober Test among each group after 1 and 3 
Table 1 Demographic data of the two studied groups

\begin{tabular}{|c|c|c|c|c|c|c|}
\hline \multirow{2}{*}{$\begin{array}{l}\text { Variable } \\
\text { Age (years) }\end{array}$} & \multicolumn{2}{|c|}{ Group I (US) $(n=59)$} & \multicolumn{2}{|c|}{ Group II (FL) $(n=62)$} & \multirow[t]{2}{*}{$t$} & \multirow[t]{2}{*}{$p$} \\
\hline & & & & & & \\
\hline Mean \pm SD & \multicolumn{2}{|c|}{$42.53 \pm 10.30$} & \multicolumn{2}{|c|}{$42.69 \pm 10.48$} & \multirow[t]{3}{*}{0.09} & 0.93 \\
\hline Median & 42 & & 43 & & & NS \\
\hline Range & $23-6$ & & $22-62$ & & & \\
\hline \multicolumn{7}{|l|}{ BMI $\left(\mathrm{kg} / \mathrm{m}^{2}\right)$} \\
\hline Mean \pm SD & \multicolumn{2}{|c|}{$30.63 \pm 4.02$} & \multicolumn{2}{|c|}{$30.45 \pm 3.92$} & 0.24 & 0.81 \\
\hline Median & \multicolumn{2}{|c|}{30.5} & \multicolumn{2}{|l|}{30} & & NS \\
\hline Range & \multicolumn{2}{|c|}{$22-39$} & \multicolumn{2}{|c|}{$23.8-39.4$} & & \\
\hline Variable & No & $\%$ & No & $\%$ & $x^{2}$ & $p$ \\
\hline \multicolumn{7}{|l|}{ Age group } \\
\hline$<40$ years & 25 & 42.4 & 21 & 33.9 & \multirow[t]{2}{*}{0.93} & 0.34 \\
\hline$\geq 40$ years & 34 & 57.6 & 41 & 66.1 & & NS \\
\hline \multicolumn{7}{|l|}{ BMI } \\
\hline Normal (18-25) & 4 & 6.8 & 4 & 6.5 & & \\
\hline Over weight > 25-30) & 24 & 40.7 & 28 & 45.2 & \multirow[t]{2}{*}{0.25} & 0.88 \\
\hline Obese (> 30) & 31 & 52.5 & 30 & 48.4 & & NS \\
\hline \multicolumn{7}{|l|}{ Sex } \\
\hline Female & 34 & 57.6 & 36 & 58.1 & \multirow[t]{2}{*}{0.002} & 0.96 \\
\hline Male & 25 & 42.4 & 26 & 41.9 & & NS \\
\hline
\end{tabular}

SD standard deviation, $t$ independent $t$ test, $x^{2}$ chi-squared test, NS non-significant $(p>0.05)$

months of injection versus initial assessment. No statistical significance difference was found between Modified Schober Test value at 1 month and 3 months in both groups. There was no statistical significant difference between two studied groups in SLRT before or after injection. However, there was statistical significant increase in SLRT among each group after 1 and 3 months of injection versus initial assessment. No statistical significance difference was found between SLRT degree at 1 month and 3 months in both groups.

As shown in Table 5, there was no statistical significant difference between two studied groups in ODI before or after injection. However, there was statistical significant decrease of ODI in each group after 1 and 3 months of injection versus initial assessment. No statistical significance difference was found between ODI values at 1 month and 3 months in both groups.

Table 6 showed that there was no statistical significant difference between failed and succeeded cases in sex, BMI, time, Modified Schober Test, SLRT, VAS, ODI, and $\mathrm{SH}$ diameter. However, there was a statistical significant increase in age group less than 40 years and duration $<6$ months in successful cases also and there was a statistical significant increase in the frequency of target level no L2-3/L3-4 and type of lumbar disc not foraminal type among successful cases.
As shown in Table 7, applying multivariate analysis of all significant factors in univariate analysis and declares that the significant predictors of a successful outcome in the studied groups were duration $<6$ months, target level not L2-3/L3-4, and LDP other than foraminal type. However, age $<40$ years was found to be non-significant in predicting a successful outcome.

\section{Complications}

1) One patient in Group 1 suffered from dizziness and headache immediately following the intervention which was relieved by paracetamol tablets.

2) Two patients in Group 2: one suffered from syncopal attack following the intervention and the other one suffered from dizziness and headache and received oral paracetamol.

\section{Discussion}

Lumbar epidural steroid injection as part of the conservative management of radicular pain due to disc herniation is extremely popular in everyday clinical practice. The lumbar epidural space is accessible either by caudal, inter-laminar, or transforaminal routes [9].

The caudal epidural injection has numerous advantages such as a lower risk of dural or subarachnoid penetration, efficacy in multilevel disc prolapse, and greater 
Table 2 Duration of disease, time of procedure, target level, and type of LDP among the two groups and SH diameter in the US

\begin{tabular}{|c|c|c|c|c|c|c|}
\hline Variable & \multicolumn{2}{|c|}{ Group I (US) ( $n=59)$} & \multicolumn{2}{|c|}{ Group II (FL) $(n=62)$} & Test & $p$ \\
\hline \multicolumn{5}{|l|}{ Duration (months) } & MW & \\
\hline Mean \pm SD & \multicolumn{2}{|l|}{$5.95 \pm 2.5$} & \multicolumn{2}{|c|}{$5.82 \pm 2.53$} & & \\
\hline Median & \multicolumn{2}{|l|}{5} & \multicolumn{2}{|l|}{5} & 0.60 & 0.55 \\
\hline Range & \multicolumn{2}{|l|}{$2-11$} & \multicolumn{2}{|c|}{$2-11$} & & NS \\
\hline \multicolumn{5}{|l|}{ Time of procedure (min) } & $t$ & $<0.001^{* *}$ \\
\hline Mean \pm SD & \multicolumn{2}{|l|}{$6.10 \pm 0.71$} & \multicolumn{2}{|c|}{$11.52 \pm 1.14$} & 31.28 & \\
\hline Median & \multicolumn{2}{|l|}{6} & \multicolumn{2}{|l|}{11.5} & & \\
\hline Range & \multicolumn{2}{|l|}{$5-8$} & \multicolumn{2}{|c|}{$10-13.5$} & & \\
\hline \multicolumn{7}{|l|}{ Sacral hiatus diameter } \\
\hline Mean \pm SD & \multicolumn{4}{|l|}{$4.69 \pm 1.69$} & & \\
\hline Median & \multicolumn{2}{|l|}{4.9} & \multicolumn{2}{|l|}{-} & - & - \\
\hline Range & \multicolumn{4}{|l|}{$1.3-8.9$} & & \\
\hline Variable & No & $\%$ & No & $\%$ & $x^{2}$ & $p$ \\
\hline \multicolumn{7}{|l|}{ Duration (months) } \\
\hline$<6$ & 34 & 57.6 & 35 & 56.5 & 0.02 & 0.90 \\
\hline$\geq 6$ & 25 & 42.4 & 27 & 43.5 & & NS \\
\hline \multicolumn{7}{|l|}{ Target level } \\
\hline $\mathrm{L} 2-3 / \mathrm{L} 3-4$ & 4 & 6.8 & 5 & 8.1 & & \\
\hline$\llcorner 4-5$ & 15 & 25.4 & 16 & 25.8 & & \\
\hline$\llcorner 4-5 / L 5-S 1$ & 25 & 42.4 & 26 & 41.9 & 0.09 & 0.99 \\
\hline L5-S1 & 15 & 25.4 & 15 & 24.2 & & NS \\
\hline \multicolumn{7}{|l|}{ Type of lumbar disc } \\
\hline Central & 37 & 62.7 & 38 & 61.3 & & \\
\hline Diffuse & 17 & 28.8 & 18 & 29 & 0.06 & 0.97 \\
\hline Foraminal & 5 & 8.5 & 6 & 9.7 & & NS \\
\hline
\end{tabular}

$S D$ standard deviation, MW Mann-Whitney test, $t$ independent $t$ test, $\chi^{2}$ chi-squared test, $N S$ non-significant $(p>0.05)$

**Highly significant $(p<0.01)$

ease of execution in patients with a history of previous spinal surgery [7].

Our results run with that published by Parket al [19],. Park et al. [8], and Akkaya et al. [20] who reported that variances among age, BMI, sex distribution, and duration of disease were non-significant between the US and FL groups.

Although Park et al. [8] mentioned that one of his study limitations is that US-guided CESI was done in patients with BMI $<30 \mathrm{~kg} / \mathrm{m}^{2}$, in our study, obesity was not necessarily associated with difficult CESI. Patients with a mean of BMI $\geq 30 \mathrm{~kg} / \mathrm{m}^{2}$ were included in our study in both groups. However, none had thick subcutaneous fat in the sacral area, which could hinder ultrasonography. A curved transducer for deeper structures was also used in the present study. Blanchais et al. [21] reported easy identification of the $\mathrm{SH}$ in obese patients by US.

Such finding coincides with that published by Nikooseresht et al [22] who stated that $67.6 \%$ of their patients were overweight or pre-obese and did not observe excessive fat tissue overlying the sacrum to make the anatomic details of the $\mathrm{SH}$ invisible.

Our results were similar to those obtained by Akkaya et al. [20] who also reported a statistical significant increase in time of procedure among FL group. This could be attributed to that caudal anatomy can be visualized in more detail with US. Using US, the average time span from locating the sacral hiatus to the insertion of the needle into the caudal epidural space was less than $2 \mathrm{~min}$. Under US guidance, chiefly only one attempt is needed in guiding the needle into the caudal epidural space. However, FL is used for many shots and injecting of contrast media and imaging span more time.

The SH could only be measured in the US group and could not be measured in the FL group.

Comparing variances in the target root levels and type of LDP revealed non-significant values among the two studied groups. 
Table 3 Visual analogue scale of the two studied groups

\begin{tabular}{|c|c|c|c|c|}
\hline Variable & Group I (US) ( $n=59)$ & Group II (FL) (n=62) & Test & $p$ \\
\hline Before (mm) & & & $\mathrm{t}$ & \\
\hline Mean \pm SD & $70.31 \pm 7.49$ & $71.69 \pm 5$ & 1.20 & 0.23 \\
\hline Median & 70 & 71.5 & & NS \\
\hline Range & $59-82$ & $59-82$ & & \\
\hline 1 month (mm) & & & MW & \\
\hline Mean \pm SD & $23.85 \pm 21.07$ & $24.03 \pm 23.51$ & & \\
\hline Median & 15 & 14 & 0.84 & 0.40 \\
\hline Range & $5-74$ & $3-77$ & & NS \\
\hline 3 months (mm) & & & MW & \\
\hline Mean \pm SD & $27.73 \pm 24.99$ & $26.84 \pm 25.30$ & & \\
\hline Median & 14 & 13.5 & 0.78 & 0.43 \\
\hline Range & $4-79$ & $4-75$ & & NS \\
\hline$P^{1 \$}$ & $<0.001^{* *}$ & $<0.001 * *$ & & \\
\hline $\mathrm{P}^{2 \$}$ & $<0.001^{* *}$ & $<0.001^{* *}$ & & \\
\hline$P^{3 \$}$ & $0.65 \mathrm{NS}$ & $0.41 \mathrm{NS}$ & & \\
\hline
\end{tabular}

SD standard deviation, $t$ independent $t$ test, MW Mann-Whitney test, NS non-significant $(p>0.05), P 1$ before versus 1 month, $P 2$ before versus 3 months, $P 31$ month versus 3 months of test

**Highly significant $(p<0.01)$

\$Paired Wilcoxon test

Similar results were obtained by Park et al. [19], Park et al. [8], and Akkaya et al. [20] who found variances in target root level and LDP types were non-significant between the two studied groups.

Regarding Modified Schober Test and SLRT as clinical assessment tests, VAS, and ODI, non-significant statistical differences were observed between the US and FL groups before injections.

These findings are in a close agreement with that presented by Nandi and Chowdhery [9] who also used Modified Schober Test and straight leg raising test as indicators for clinical assessment before and after CESI and reported a non-significant difference before injection in their two studied groups. Moreover, the obtained results are in harmony with that detected by Park et al. [19], Park et al. [8], Hazra et al. [23], and Akkaya et al. [20] who reported non-significant differences between the US and FL groups as regards VAS and ODI before injections.

In our work, there was highly statistical significant improvement in Modified Schober Test, SLRT, VAS, and ODI at 1 month and 3 months after injection versus before injection in the two groups. The results in the present study are consistent with the previous observations of Park et al. [19], Park et al. [8], Hazra et al. [23], and Akkaya et al. 2017 [20] who demonstrated significant improvement of pain and function in the US- and FL-guided CESI as denoted by improvement in VAS and ODI after injections versus before injection.
Additionally, Nandi and Chowdhery 2017 [9] reported a significant statistical difference in the SLRT, modified Schober test, VAS, and ODI before versus 1 month after CESI and before versus 3 months after CESI in his randomized controlled clinical trial to detect the effectiveness of CESI.

There have been numerous beliefs on the mechanism of ESI. Experimentally, radicular pain occurs owing to both mechanical compression and chemical radiculitis with the effect of inflammatory cytokines on the dorsal root ganglion. Therefore, local delivery of corticosteroid and local anesthesia to the affected nerve root seems to be a rationale option [24].

It is stated that the steroid lipophilic characteristic allows sustained release from the abundant epidural fat, where the steroid is injected [25].

Accordingly, corticosteroid reduces nerve swelling and upregulates the transcription of anti-inflammatory genes, in contrast to local analgesics, which are responsible for instant pain relief [26].

The current results showed non-statistical significant difference between the US and FL groups as regards Modified Schober Test, SLRT, VAS, and ODI at 1 and 3 months after injection.

This is well in line with the results of Park et al. [19], Park et al. [19], Hazra et al. [23], and Akkaya et al. [20] who stated that there was no statistical significant improvement between the US- and FL-guided CESI in pain and function as denoted by improvement in VAS and ODI after injections. 
Table 4 Clinical tests of the two studied groups

\begin{tabular}{|c|c|c|c|c|}
\hline Variable & Group I (US) ( $n=59$ ) & Group II (FL) (n=62) & $t$ & $p$ \\
\hline \multicolumn{5}{|c|}{ Modified Schober Test } \\
\hline \multicolumn{5}{|l|}{ Before $(\mathrm{cm})$} \\
\hline Mean \pm SD & $3.23 \pm 1.08$ & $3.33 \pm 1.11$ & 0.44 & 0.66 \\
\hline Median & 3 & 3.15 & & NS \\
\hline Range & $1.5-6$ & $1.5-7$ & & \\
\hline \multicolumn{5}{|l|}{1 month $(\mathrm{cm})$} \\
\hline Mean \pm SD & $6.16 \pm 1.55$ & $6.11 \pm 1.64$ & 0.17 & 0.87 \\
\hline Median & 6 & 6.5 & & NS \\
\hline Range & $2-9$ & $2-10$ & & \\
\hline \multicolumn{5}{|l|}{3 months $(\mathrm{cm})$} \\
\hline Mean \pm SD & $5.98 \pm 1.81$ & $5.91 \pm 1.87$ & 0.23 & 0.82 \\
\hline Median & 6 & 6.5 & & NS \\
\hline Range & $2-9$ & $2-10$ & & \\
\hline$P^{1 \#}$ & $<0.001^{* *}$ & $<0.001^{* *}$ & & \\
\hline$P^{2 \#}$ & $<0.001^{* *}$ & $<0.001^{* *}$ & & \\
\hline$P^{3 \#}$ & $0.18 \mathrm{NS}$ & 0.09 NS & & \\
\hline \multicolumn{5}{|c|}{ Straight leg raising test } \\
\hline \multicolumn{5}{|l|}{ Before $(\mathrm{cm})$} \\
\hline Mean \pm SD & $3.23 \pm 1.08$ & $3.33 \pm 1.11$ & 0.44 & 0.66 \\
\hline Median & 3 & 3.15 & & NS \\
\hline Range & $1.5-6$ & $1.5-7$ & & \\
\hline \multicolumn{5}{|l|}{1 month $(\mathrm{cm})$} \\
\hline Mean \pm SD & $6.16 \pm 1.55$ & $6.11 \pm 1.64$ & 0.17 & 0.87 \\
\hline Median & 6 & 6.5 & & NS \\
\hline Range & $2-9$ & $2-10$ & & \\
\hline \multicolumn{5}{|l|}{3 months $(\mathrm{cm})$} \\
\hline Mean \pm SD & $5.98 \pm 1.81$ & $5.91 \pm 1.87$ & 0.23 & 0.82 \\
\hline Median & 6 & 6.5 & & NS \\
\hline Range & $2-9$ & $2-10$ & & \\
\hline$P^{1 \#}$ & $<0.001^{* *}$ & $<0.001^{* *}$ & & \\
\hline $\mathrm{P}^{2 \#}$ & $<0.001^{* *}$ & $<0.001^{* *}$ & & \\
\hline$P^{3 \#}$ & 0.18 NS & 0.09 NS & & \\
\hline
\end{tabular}

$S D$ standard deviation, $t$ independent $t$ test, NS non-significant $(p>0.05), P 1$ before versus 1 month, $P 2$ before versus 3 months, $P 31$ month versus 3 months of test

**Highly significant $(p<0.01)$

"Paired $t$ test

The advantages of US are that it is easy to use, radiation-free, and can be utilized virtually in any clinical setting. Most significantly, US can give real-time and continuous needle guiding images without exposure to radiation. The blood vessels could be identified by power Doppler imaging. With the use of the US, a needle trajectory that avoids the blood vessels and other structures can be selected from the start [10].

Chen et al. [27] reported accuracy and feasibility in needle placement utilizing a high-frequency US transducer to recognize the SH during CESI. US can acquire clear images of the $\mathrm{SH}$ and detect the anatomic variations of the sacrum and $\mathrm{SH}$ that make CESI difficult or impossible and in the terms of saving procedure time make.

Exclusively, US provides accurate anatomic information about the site of the injection. US allows measurement of the depth of the SH and the distance from the skin to the SCL and $\mathrm{SH}$ for precise needle placement. The diameter of the SH has been observed to be $4.6 \mathrm{~mm}$ 
in adults. Diameters less than $2 \mathrm{~mm}$ can result in a higher failure rate in performing CESI $[22,20]$.

Sacral hiatus has been reported to be absent in minimal cases. Failure of CESI was observed in such cases [28].

In our study, the $\mathrm{SH}$ was identified in all patients (100.0\%) in the US group.

Color Doppler US-guided injections can also visualize intravascular injections. Intravascular hemorrhage has been reported in $11-42 \%$ of the FL-guided caudal epidural interventions [29].

Park et al. [19] used live FL during injection of 1 to 2 contrast media with color Doppler mode. They could achieve an accurate position of contrast media dye in the epidural space and no instance of intravascular injection in all 60 subjects by using the color Doppler spectrum confirmation method during live FL.

Compared to the FL-guided procedure, the US-guided procedure has few hinders. In the case of unilateral radicular pain, a diminished therapeutic impact could be expected, if a drug might be administered to the opposite site. On the other hand, FL-guided procedure has an advantage that correcting the direction of the needle is possible in account of identifying incorrect drug administration [8].

To overcome the limitation of the US-guided procedure, experts in CESI have recommended inserting the needle toward the affected side in order to convey the medication toward the affected side and to increase the possibility that the medication will achieve the site of the pathology [30].
Situating the patient in the lateral decubitus on the side of their leg pain results in accumulation of the infused drugs on the dependent side due to gravity and can resolve the problem. Makki, et al. [31] declared that laying a patient on the side of their leg pain after CESI beneficially affects the degree of pain alleviation.

In our study, we overcome this limitation also via changing the US transducer position after introducing the needle by placing it transversely across the $\mathrm{SH}$ and obtaining the image of the two sacral cornua with the needle out of plane. While we inject the material, the injectate will appear to the right, to the left, or to the center, and then, we can modify the position of the needle to the affected side.

Another limitation of the US is that it cannot provide information concerning the injectate diffusion during CESI as FL. However, unidirectional flow (defined as one dominant color on color Doppler image) is predictive of successful CESI [10].

In the present study, we recorded minimal complications in the form of dizziness and transient headache with only one recorded case of vasovagal attack Caudal epidural injections are considered as the safest and easiest procedures of epidurals with minimal risk of coincidental dural puncture [7].

Concerning cases that were not improved from the injection, there are possible causes of failure of the procedure. Individual variations of receptor response to steroids might occur and affect the outcome [23].

Table 5 Oswestry Disability Index of the two studied groups

\begin{tabular}{|c|c|c|c|c|}
\hline Variable & Group I (US) ( $n=59)$ & Group II (FL) $(n=62)$ & Test & $p$ \\
\hline Before (\%) & & & $t$ & \\
\hline Mean \pm SD & $55.29 \pm 7.39$ & $55.73 \pm 6.54$ & 0.34 & 0.73 \\
\hline Median & 55.3 & 55.7 & & NS \\
\hline Range & $40.70-69.20$ & $42.3-68.5$ & & \\
\hline 1 month (\%) & & & MW & \\
\hline Mean \pm SD & $21.15 \pm 16.21$ & $22.04 \pm 16.78$ & & \\
\hline Median & 14.5 & 15.9 & 0.38 & 0.70 \\
\hline Range & $5.8-60$ & $5.7-64.5$ & & NS \\
\hline 3 months (\%) & & & MW & \\
\hline Mean \pm SD & $23.77 \pm 20.22$ & $25.82 \pm 21.07$ & & \\
\hline Median & 12.6 & 15.6 & 1.27 & 0.20 \\
\hline Range & $5.8-64.5$ & $6.2-67.60$ & & NS \\
\hline$P^{15}$ & $<0.001^{* *}$ & $<0.001^{* *}$ & & \\
\hline$P^{2 S}$ & $<0.001^{* *}$ & $<0.001 * *$ & & \\
\hline$P^{3 \$}$ & $0.43 \mathrm{NS}$ & $0.06 \mathrm{NS}$ & & \\
\hline
\end{tabular}

SD standard deviation, $t$ independent $t$ test, MW Mann-Whitney test, NS non-significant $(p>0.05), P 1$ before versus 1 month, $P 2$ before versus 3 months, $P 31$ month versus 3 months

**Highly significant $(p<0.01)$

\$Paired Wilcoxon test 
Table 6 Relation between demographic data, disease duration, time of procedure, and target level baseline data of the studied cases and outcome

\begin{tabular}{|c|c|c|c|c|c|c|}
\hline Variable & & Succeed $(n=86)$ & Failed $(n=35)$ & Test & $p$ & OR $(95 \% \mathrm{Cl})$ \\
\hline \multirow[t]{2}{*}{ Age (years) } & $<40, N(\%)$ & $38(44.2 \%)$ & $8(22.9 \%)$ & $x^{2}$ & & \\
\hline & $\geq 40, N(\%)$ & $48(55.8 \%)$ & $27(77.1 \%)$ & 4.80 & $0.03^{*}$ & $2.67(1.09-6.55)$ \\
\hline \multirow[t]{3}{*}{ BMI $\left(\mathrm{kg} / \mathrm{m}^{2}\right)$} & Normal, $N(\%)$ & $7(8.1 \%)$ & $1(2.9 \%)$ & $x^{2}$ & & 1 \\
\hline & Overweight, $N(\%)$ & $36(41.9 \%)$ & $16(45.7 \%)$ & 0.15 & $0.56 \mathrm{NS}$ & $3.11(0.35-7.70)$ \\
\hline & Obese, N (\%) & $43(50 \%)$ & $18(51.4 \%)$ & & & $2.93(0.34-5.57)$ \\
\hline \multirow[t]{2}{*}{ Sex } & Female, $N(\%)$ & $51(59.3 \%)$ & $19(54.3 \%)$ & $x^{2}$ & & \\
\hline & Male, N (\%) & $35(40.7 \%)$ & $16(45.7 \%)$ & 0.26 & $0.61 \mathrm{NS}$ & $1.23(0.56-2.71)$ \\
\hline \multirow[t]{2}{*}{ Procedure } & US, N (\%) & $42(48.8 \%)$ & $17(48.6 \%)$ & $x^{2}$ & & \\
\hline & $\mathrm{FL}, N(\%)$ & $44(51.2 \%)$ & $18(51.4 \%)$ & 0.01 & 0.98 NS & $1.01(0.46-2.22)$ \\
\hline \multirow[t]{2}{*}{ Duration (months) } & $<6$ & $56(65.1 \%)$ & $13(37.1 \%)$ & $x^{2}$ & & \\
\hline & $\geq 6$ & $30(34.9 \%)$ & $22(62.9 \%)$ & 7.94 & $0.005^{* *}$ & $3.16(1.40-7.15)$ \\
\hline \multirow[t]{2}{*}{ Time of procedure: (min.) } & Mean \pm SD & $8.81 \pm 2.85$ & $9.03 \pm 3$ & $\mathrm{t}$ & & \\
\hline & Range & $5-13.5$ & $5-13.5$ & 0.39 & $0.70 \mathrm{NS}$ & - \\
\hline \multirow[t]{4}{*}{ Target level } & L2-3/L3-4, N (\%) & $2(2.3 \%)$ & 7 (20\%) & $x^{2}$ & & 10.63 \\
\hline & $\llcorner 4-5, N(\%)$ & $23(26.7 \%)$ & $8(22.9 \%)$ & & & $(2.09-24.14)$ \\
\hline & L4-5/L5-S1, N (\%) & $38(44.2 \%)$ & 13(37.1\%) & 11.34 & $0.01 *$ & \\
\hline & L5-S1, N (\%) & $23(26.7 \%)$ & $7(20 \%)$ & & & \\
\hline \multirow[t]{3}{*}{ Type of lumbar disc } & Central, N (\%) & $57(66.3 \%)$ & $18(51.4 \%)$ & & & \\
\hline & Diffuse, N (\%) & $26(30.2 \%)$ & $9(25.7 \%)$ & 11.33 & $0.003^{* *}$ & 8.20 \\
\hline & Foramen, $N(\%)$ & $3(3.5 \%)$ & $8(22.9 \%)$ & & & $(2.03-23.11)$ \\
\hline \multirow[t]{2}{*}{ Schober Test before $(\mathrm{cm})$} & Mean \pm SD & $3.5 \pm 1.43$ & $3.09 \pm 1.23$ & $\mathrm{t}$ & & \\
\hline & Range & $1.8-7$ & $1.5-6.5$ & 1.49 & $0.14 \mathrm{NS}$ & - \\
\hline \multirow[t]{2}{*}{ Straight leg raising $(\stackrel{\circ}{)}$} & Mean \pm SD & $50.03 \pm 15.92$ & $46.07 \pm 10.02$ & $\mathrm{t}$ & & \\
\hline & Range & $30-75$ & $30-70$ & 1.36 & $0.18 \mathrm{NS}$ & - \\
\hline \multirow[t]{2}{*}{ VAS (mm) } & Mean \pm SD & $70.70 \pm 6.11$ & $71.8 \pm 6.93$ & $\mathrm{t}$ & & \\
\hline & Range & $59-82$ & $59-82$ & 0.87 & $0.39 \mathrm{NS}$ & - \\
\hline \multirow[t]{2}{*}{ Oswestry Disability Index (\%) } & Mean \pm SD & $55.27 \pm 6.75$ & $56.11 \pm 7.64$ & $\mathrm{t}$ & & \\
\hline & Range & $40.70-69.2$ & $42.7-68.5$ & 0.61 & $0.55 \mathrm{NS}$ & - \\
\hline \multirow[t]{3}{*}{ Sacral hiatus diameter } & & $(n=42)$ & $(n=17)$ & MW & & \\
\hline & Mean \pm SD & $4.68 \pm 1.52$ & $4.71 \pm 2.09$ & 0.42 & $0.68 \mathrm{NS}$ & - \\
\hline & Range & $1.8-8.9$ & $1.3-8$ & & & \\
\hline
\end{tabular}

SD standard deviation, $t$ independent $t$ test, MW Mann-Whitney test, $\chi^{2}$ chi-squared test, NS non-significant $(p>0.05)$

*Significant $(p<0.05)$

**Highly significant $(p<0.01)$

Table 7 Logistic regression analysis for significant predictors of successful procedure among the studied group

\begin{tabular}{|c|c|c|c|c|c|c|c|}
\hline \multirow[t]{2}{*}{ Variable } & \multirow[t]{2}{*}{ B } & \multirow[t]{2}{*}{ S.E. } & \multirow[t]{2}{*}{ Wald } & \multirow[t]{2}{*}{$\mathbf{P}$} & \multirow[t]{2}{*}{ OR } & \multicolumn{2}{|c|}{ 95.0\% C.I. } \\
\hline & & & & & & Lower & Upper \\
\hline Young age ( $<40$ years) & -0.02 & 0.03 & 0.78 & 0.38 & 0.98 & 0.93 & 1.03 \\
\hline Duration $<6$ months & 0.95 & 0.55 & 1.93 & $0.03^{*}$ & 2.25 & 1.04 & 4.71 \\
\hline Target level, not L2-3/L3-4 & 1.29 & 0.72 & 3.14 & $<0.001^{* *}$ & 4.13 & 2.67 & 10.76 \\
\hline LDP other than foraminal type & 1.15 & 0.63 & 3.02 & $0.002^{* *}$ & 3.78 & 2.05 & 7.84 \\
\hline
\end{tabular}

$B$ beta, S.E standard error, Wald wald test, $P p$ value, OR odds ratio, C.I confidence interval, NS non-significant $(p>0.05)$

*Significant $(p<0.05)$

**Highly significant $(p<0.01)$ 
Several studies report that $\mathrm{SH}$ with diameters less than $2 \mathrm{~mm}$ is associated with a high failure rate of CESI [19].

As well, Chen et al. [27] reported that $\mathrm{SH}$ with diameters ranging from 1.2 to $1.6 \mathrm{~mm}$ might indicate a higher failure rate in performing CESI.

In our work, three cases with failed injection in the US group were measured to have SH diameter less than 1.7 $\mathrm{mm}$.

There are possible causes of failure of the procedure. Individual variations of receptor response to steroid might occur and affect the outcome [23].

Several studies report that $\mathrm{SH}$ with diameters less than $2 \mathrm{~mm}$ is associated with a high failure rate of CESI [19].

As well, Chen et al. [27] reported that $\mathrm{SH}$ with diameters ranging from 1.2 to $1.6 \mathrm{~mm}$ might indicate a higher failure rate in performing CESI.

In our work, three cases with failed injection in the US group were measured to have $\mathrm{SH}$ diameter less than 1.7 $\mathrm{mm}$.

Some patients were heavy workers, and others might have a more sedentary lifestyle which also may affect the outcome.

In analysis our results, it was declared that duration < 6 months, target level not L2-3/L3-4, -ve FST and LDP other than foraminal type and age $<40$ years were significant predictors for a successful outcome in the studied groups.

However, significant predictors of success regarding age were found to be non-significant when applying multivariate analysis of the results.

\section{Study limitations}

To put in our minds, this is the first study conducted on the Egyptian population to compare the effectiveness of US-guided CESI versus the FL-guided CESI in LDP with radiculopathy refractory to conservative treatment. However, this research has several limitations.

First, both procedures were performed by one physician, reflecting the experience of 1 practitioner and limiting the generalization of the study results.

Second, we did not repeat steroid epidural injections as per the recommendations of the North American Spine Society Guidelines [32]. However, recent studies mentioned that some patients might benefit from the repeated injection [33].

Third, a follow-up MRI of the patients, to assess changes in disc morphology and the possible effects of the injection, may be valuable. Such a study could help us to understand whether the success of ESI is related to herniated disc resorption or whether the patients still have a sizable LDP and their clinical improvement is due to inflammatory response modulation to the herniation.
Fourth, although statistical requirements were considered in deciding the number of the subjects in each group, the larger number of cases and the longer duration of follow-up may be needed to improve the limitations of this study.

\section{Conclusion}

US-guided CESI proved to be effective and with the same efficacy as fluoroscopy-guided CESI in the treatment of refractory lumbar disc with radiculopathy.

\section{Recommendation}

1. Further studies are needed on a larger number of cases and for a longer duration of follow-up.

2. Follow-up MRI of the patients to assess changes in disc morphology and the possible effects of the injection.

\section{Supplementary Information}

The online version contains supplementary material available at https://doi. org/10.1186/s43055-020-00388-8.

Additional file 1: Epidural supplementary figure. Supplementary Fig

1: Ultrasound imaging of sacrum at the sacral hiatus level.

Supplementary Fig 2: Ultrasound image of sacral canal.

Supplementary Fig 3: Ultrasound image at the sacral hiatus.

Supplementary Fig 4: Fluoroscopically guided caudal epidural injection

of contrast medium before administration of the injectate.

\section{Abbreviations}

BMI: Body mass index; CESI: Caudal epidural steroid injection; ESI: Epidural steroid injection; FL: Fluoroscopy; LBP: Low back pain; LDP: Lumbar disc prolapse; MRI: Magnetic resonance imaging; ODI: Oswestry disability index; SC: Sacral canal; SCL: Sacrococcygeal ligament; SH: Sacral hiatus; SLRT: Straight leg raising test; US: Ultrasound; VAS: Visual analog scale

\section{Acknowledgements}

All authors wish to express great appreciation to all cooperative patients who participated in this study.

\section{Authors' contributions}

$M E, R S$, and EE were responsible for the idea, study design, patient selection, and examination. AA was responsible for the radiological assessment. ME was responsible for intervention, and RS was responsible for pain and function assessment. All authors have contributed to the concept and design of the study, interpretation of the data and revising the manuscript, and have approved the final draft.

\section{Funding}

This study was totally funded by all authors. All authors are responsible for the payment of publication fees. All authors declare that they did not receive any financial support.

\section{Availability of data and materials}

The data analyzed for this study are available from the corresponding author on request.

\section{Ethics approval and consent to participate}

The present study was conducted in agreement with the guidelines of the Declaration of Helsinki. A written consent was obtained from each participant sharing in this study. The institutional research board of faculty of medicine, Mansoura University, approved this study, code: MS/16.06.46. 


\section{Consent for publication}

All patients included in this research gave written informed consent to publish the data contained within this study. If the patients were less than 16 years old, deceased, or unconscious when consent for publication was requested, written informed consent for the publication of this data was given by their parent or legal guardian.

\section{Competing interests}

All authors declare that they have no conflict of interest.

\section{Author details}

${ }^{1}$ Faculty of Medicine, Department of Rheumatology and Rehabilitation, Mansoura University, Mansoura, Egypt. ${ }^{2}$ Faculty of Medicine, Department of Radiodiagnosis, Mansoura University, Mansoura, Egypt.

Received: 25 October 2020 Accepted: 13 December 2020

Published online: 01 January 2021

\section{References}

1. Liu CC, Zhang XS, Ruan YT, Huang ZX, Zhang SB, Liu M et al (2017) Accumulation of methylglyoxal increases the advanced glycation endproduct levels in DRG and contributes to lumbar disk herniation-induced persistent pain. J Neurophysiol 118(2):1321-1328

2. Thackeray A, Fritz JM, Lurie JD, Zhao W, Weinstein JN (2017) Nonsurgical treatment choices by individuals with lumbar intervertebral disc herniation in the United States: associations with long-term outcomes. Am J Phys Med Rehabil 96(8):557-564

3. Abraham P, Rennert RC, Martin JR, Ciacci J, Taylor W, Resnick D et al (2016) The role of surgery for treatment of low back pain: insights from the randomized controlled Spine Patient Outcomes Research Trials. Surg Neurol Int 7:38

4. Van de Kelft E (2016) Herniated Lumbar Disk Evaluation and Surgical Management. In: van de Kelft E (ed) Surgery of the spine and spinal cord: a neurosurgical approach. Springer International Publishing, Cham, pp 425429

5. Patel SA, Wilt Z, Gandhi SD, Rihn JA (2016) Cost-effectiveness of treatments for lumbar disc herniation. Seminars Spine Surg 28(1):53-56

6. Manchikanti L, Knezevic NK, Boswell M, Hirsch J (2016) Epidural injections for lumbar radiculopathy and spinal stenosis: a comparative systematic review and meta-analysis. Pain Physician 19:E365-E410

7. Pountos I, Panteli M, Walters G, Bush D, Giannoudis PV (2016) Safety of epidural corticosteroid injections. Drugs R\&D 16(1):19-34

8. Park G-y, Kwon DR, Cho HK (2015) Anatomic differences in the sacral hiatus during caudal epidural injection using ultrasound guidance. J Ultrasound Med 34(12):2143-2148

9. Nandi J, Chowdhery A (2017) A randomized controlled clinical trial to determine the effectiveness of caudal epidural steroid injection in lumbosacral sciatica. J Clin Diagn Res 11(2):RC04-RC08

10. Kao S-C, Lin C-S (2017) Caudal epidural block: an updated review of anatomy and techniques. Biomed Res Int. https://doi.org/10.1155/2017/ 9217145

11. Park KD, Kim TK, Lee WY, Ahn J, Koh SH, Park Y (2015) Ultrasound-guided versus fluoroscopy-guided caudal epidural steroid injection for the treatment of unilateral lower lumbar radicular pain: case-controlled, retrospective, comparative study. Medicine. 94(50):e2261

12. Wassenaar M, van Rijn RM, van Tulder MW et al (2012) Magnetic resonance imaging for diagnosing lumbar spinal pathology in adult patients with low back pain or sciatica: a diagnostic systematic review. Eur Spine J 21:220-227. https://doi.org/10.1007/s00586-011-2019-8

13. Bicket MC, Horowitz JM, Benzon HT, Cohen SP (2015) Epidural injections in prevention of surgery for spinal pain: systematic review and meta-analysis of randomized controlled trials. Spine J 15(2):348-362

14. Aggarwal A, Aggarwal A, Sahni D (2009) Morphometry of sacral hiatus and its clinical relevance in caudal epidural block. Surg Radiol Anat 31(10):793

15. Jensen MP, Karoly P, Braver S (1986) The measurement of clinical pain intensity: a comparison of six methods. Pain. 27:117-126

16. De Luigi AJ, Fitzpatrick KF (2011) Physical examination in radiculopathy. Phys Med Rehabil Clin N Am 22(1):7-40

17. Geller M, Mibielli MA, Nunes CP, da Fonseca AS, Goldberg SW, Oliveira L (2016) Comparison of the action of diclofenac alone versus diclofenac plus
B vitamins on mobility in patients with low back pain. J Drug Assess 5(1):1-

18. Fairbank JC, Pynsent PB (2000) The Oswestry Disability Index. Spine. 25(22): 2940-2953

19. Park Y, Lee J-H, Park KD, Ahn JK, Park J, Jee H (2013) Ultrasound-guided vs. fluoroscopy-guided caudal epidural steroid injection for the treatment of unilateral lower lumbar radicular pain: a prospective, randomized, singleblind clinical study. Am J Phys Med Rehabil 92(7):575-586

20. Akkaya T, Ozkan D, Kertmen H, Sekerci Z (2017) Caudal epidural steroid injections in postlaminectomy patients: comparison of ultrasonography and fluoroscopy. Turk Neurosurg 27(3):420-425

21. Blanchais A, Le Goff B, Guillot P, Berthelot JM, Glemarec J, Maugars Y (2010) Feasibility and safety of ultrasound-guided caudal epidural glucocorticoid injections. Joint Bone Spine 77(5):440-444

22. Nikooseresht M, Hashemi M, Mohajerani SA, Shahandeh F, Agah M (2014) Ultrasound as a screening tool for performing caudal epidural injections. Iran J Radiol 11(2):e13262

23. Hazra AK, Bhattacharya D, Mukherjee S, Ghosh S, Mitra M, Mandal M (2016) Ultrasound versus fluoroscopy-guided caudal epidural steroid injection for the treatment of chronic low back pain with radiculopathy: a randomised, controlled clinical trial. Indian J Anaesth 60(6):388

24. Soliman AF, Hammad GA, El-gamal Rl, Al-Rabiei MA (2016) Assessment of the implication of epidural steroid injection versus other conservative measures in the management of lumbar disc herniation. Egypt Rheumatol Rehabil 43(2):53

25. Schilling LS, Markman JD (2016) Corticosteroids for pain of spinal origin. Rheum Dis Clin 42(1):137-155

26. Shim E, Lee JW, Lee E, Ahn JM, Kang Y, Kang HS (2016) Fluoroscopically guided epidural injections of the cervical and lumbar spine. RadioGraphics. 37(2):537-561

27. Chen CP, Lew HL, Tang SF (2015) Ultrasound-guided caudal epidural injection technique. Am J Phys Med Rehabil 94(1):82-84

28. Bagheri H, Govsa F (2017) Anatomy of the sacral hiatus and its clinical relevance in caudal epidural block. Surg Radiol Anat 39(9):943-951

29. Fukazawa K, Matsuki Y, Ueno H, Hosokawa T, Hirose M (2014) Risk factors related to accidental intravascular injection during caudal anesthesia. J Anesth 28(6):940-943

30. Manchikanti L, Singh V, Cash KA, Pampati V, Damron KS, Boswell MV (2011) A randomized, controlled, double-blind trial of fluoroscopic caudal epidural injections in the treatment of lumbar disc herniation and radiculitis. Spine. 36(23):1897-1905

31. Makki D, Nawabi DH, Francis R, Hamed AR, Hussein AA (2010) Is the outcome of caudal epidural injections affected by patient positioning? Spine. 35(15):E687-E690

32. Kreiner DS, Hwang SW, Easa JE, Resnick DK, Baisden JL, Bess S et al (2014) An evidence-based clinical guideline for the diagnosis and treatment of lumbar disc herniation with radiculopathy. Spine J 14(1):180-191

33. Manchikanti L, Benyamin RM (2015) Key safety considerations when administering epidural steroid injections. Pain. 5(4):261-272

\section{Publisher's Note}

Springer Nature remains neutral with regard to jurisdictional claims in published maps and institutional affiliations.

\section{Submit your manuscript to a SpringerOpen ${ }^{\circ}$ journal and benefit from:}

- Convenient online submission

- Rigorous peer review

- Open access: articles freely available online

- High visibility within the field

- Retaining the copyright to your article

Submit your next manuscript at $>$ springeropen.com 